\title{
A SEXUALIDADE FEMININA PELA PERSPECTIVA DA GESTALT- TERAPIA: UMA PESQUISA QUALITATIVA-FENOMENOLÓGICA
}

\author{
Feminine Sexuality from Gestalt-Therapy Perspective: a Qualitative and Phenomenological Research \\ Sexualidad Femenina desde la Perspectiva de la Terapia Gestalt: un Estudio Cualitativo, un Método \\ Fenomenológico
}

CíNThia Vieira MölLER

Celana Cardoso Andrade

\begin{abstract}
Resumo: A sexualidade tem sido tema de recorrentes discussões em diversos meios, incluindo a psicologia. Compreender como a mulher vivencia esse aspecto de sua vida, e como a psicoterapia na abordagem gestáltica pode influenciar sua experiência é o que se busca com esta pesquisa. Para tanto, realizou-se uma pesquisa qualitativa com uso do método fenomenológico, segundo as formulações de Amedeo Giorgi (1985). Foram feitas entrevistas semidirigidas com três mulheres, clientes de Gestalt-terapeutas. Cinco categorias foram encontradas: desenvolvimento da sexualidade, vivência da sexualidade, contato, funções de contato, e terapia, sexualidade e desenvolvimento pessoal. Conclui-se que o autoconhecimento por meio do toque é fundamental para o desenvolvimento de sua sexualidade, e que há uma ampla diversidade de vivências sexuais, desde uma desinibição em relação ao sexo, passando pela influência de fatores externos, até a assexualidade. A maior exploração das funções de contato na experiência sexual proporciona maior desenvoltura e plenitude sexual. O processo psicoterapêutico pouco influenciou a sexualidade feminina das colaboradoras, pois ela não esteve presente em suas psicoterapias, aparentemente por tratar-se de um tema resolvido para as colaboradoras.
\end{abstract}

Palavras-chave: Sexualidade feminina; Gestalt-terapia; Contato.

Abstract: Sexuality has been a constant discussion topic in different fields, including psychology. This research aims to understand how women perceive this area in their lives and how Gestalt psychotherapy may influence their experience. Therefore a qualitative research through phenomenological method was used, according to Amedeo Giorgi (1985) formulations. Interviews were conducted with three women, Gestalt-therapy clients. Five categories were found: sexuality development, sexuality experience, contact, contact functions and therapy, sexuality and personal development. It was concluded that self knowledge acquired by means of touch is fundamental for sexual development, and there is a wide variety of sexual experience, from an disinhibition to sex, through external factors influences, up to asexuality. With more exploration on contact functions in the sexual experience provides more sexual resourcefulness and fullness. The psychotherapeutic process had little influence in the feminine sexuality of the collaborators, for it was absent in the psychotherapy, apparently because this topic was resolute for the collaborators.

Keywords: Feminine Sexuality; Gestalt Therapy; Contact.

Resumen: La sexualidad ha sido un tema recurrente en los debates en diversos medios, incluyendo la psicología. Entender cómo las mujeres experimentan este aspecto de su vida, y cómo la psicoterapia em enfoque de la Gestalt puede afectar también a su experiencia es lo que es búsquedas con esta investigación. Asi hubo uma investigación cualitativa con el uso del método fenomenológica, de acuerdo com las formulaciones de Amedeo Giorgi (1985). Se hecho entrevistas semi estructuradas con tres mujeres clientes de Gestalt terapeuta. Cinco categorías se encontraron: desarrollo de la sexualidad, la experiencia de la sexualidad, contactos, funciones de contacto, y la terapia, la sexualidad y desarrollo personal. De ello se deduce que el auto-conocimiento a través del tacto es crucial para el desarrollo de su sexualidad, y que existe una amplia diversidad de experiencias sexuales, de un desinhibición en relación al sexo, de la influencia de factores externos, incluso asexualidad. Más exploración de las funciones del tacto en experiencia sexual proporciona una mayor facilidad y plenitud sexual. El proceso psicoterapêutico poço influenciado la sexualidad femenina de las colaboradores, ya que no estuvo presente en su psicoterapia, al parecer porque se trata de un asunto se resuelto de las colaboradores.

Palabras-claves: La sexualidad femenina, La terapia Gestalt; Contacto.

\section{Introdução}

Questões relativas à sexualidade têm sido alvo de muitos debates e questionamentos na atualidade (Dall'Agnol, 2003), porém, na abordagem gestáltica, área de atuação da pesquisadora, é uma questão ainda pouco tratada. Esse é tema amplamente discutido nas ciências biológicas e sociais, porém, na Gestalt-terapia são escassos os estudos nessa área. Frente a essa realidade decidiu-se, portanto, realizar esta pesquisa, com clientes de Gestalt- 
terapeutas, tratados pelo prisma teórico dessa abordagem, com o intuito de avolumar a colaboração para a discussão da sexualidade, tema recorrente na prática clínica da pesquisadora. Para compreensão do assunto, propõe-se a contextualização e melhor definição da sexualidade, de acordo com diversos autores que se dedicam ao estudo do tema.

A sociedade atual tem o hábito de pensar a sexualidade resumida ao ato sexual e ao que lhe é próximo. No entanto, essa é uma redução de algo mais amplo, pois ela também se refere a aspectos como erotismo e sensualidade (Pinto, 2002). Segundo o Ministério da Saúde (2006), a sexualidade é muito mais do que sexo, é um aspecto central da vida das pessoas e envolve sexo, papéis sexuais, orientação sexual, erotismo, prazer, envolvimento emocional, amor e reprodução.

Pinto (2002) considera a sexualidade e a identidade sexual as bases mais importantes da identidade pessoal dos indivíduos. A construção da identificação sexual, conforme Dall'Agnol (2003), é um processo que se intensifica na adolescência, tornando a tarefa fundamental dessa fase do desenvolvimento humano. Os fatores históricos, sociais e culturais influenciam fortemente a construção e a constituição de gênero (Seixas, 1998; Heilborn, Cabral \& Bozon, 2006).

A sexualidade humana, ainda de acordo com Seixas (1998), é composta pelos aspectos biológico, psicológico e social. A autora apresenta uma visão do homem como um todo, do qual a sexualidade faz parte. Esse pensamento assemelha-se com a forma de a abordagem gestáltica perceber o homem, que, segundo Lima (2008), foi influenciada pelo pensamento holístico que teve como precursor Jan Smuts, o proponente filosófico mais importante da teoria organísmica (Hall, Lindzey \& Campbell, 2000; Yontef, 1998). Holismo, segundo Chaer (2006) provém do grego holon e significa todo, totalidade. De acordo com Abbagnano (1999) trata-se de uma doutrina segundo a qual os fenômenos biológicos dependem dos fenômenos físico-químicos.

Nessa totalidade, apoiadas por um fundo, emergem figuras que compõem a existência humana. O campo perceptivo ocorre pela eleição de uma necessidade, cuja consequência natural ó o surgimento de uma figura. Entende-se por figura qualquer processo que se destaca de um fundo, aquilo que ocupa o centro da consciência (Koffka, 1975). A figura é fechada, estruturada e não se pode distingui-la sem um fundo. Esse conceito é referido diversas vezes neste trabalho, visto que a sexualidade, figura da pesquisa, é apoiada em um contexto, um fundo que é amplo e singular para cada participante, e a abordagem gestáltica se interessa por ambos e por sua interrelação (Ginger \& Ginger, 1995).

Assim, a sexualidade não pode ser entendida como resultado apenas da realidade interna do indivíduo, mas em razão do campo ao qual ele pertence. A abordagem gestáltica percebe o homem como um todo que está inserido em um campo e estuda a relação entre a pessoa e o seu meio social (Ribeiro, 1985; Ginger \& Ginger, 1995). Ela valoriza a pessoa e a sua relação com ela mesma, com o outro e com o mundo.

A sexualidade não é objeto de estudo específico na abordagem gestáltica, que, no entanto, apresenta uma atitude de acolhimento e respeito à diversidade das necessidades e dos desejos, opondo-se a normas pré-definidas (Ginger, 2007).

Com o questionamento de como a sexualidade está presente nas mulheres e como se manifesta na vida e nos consultórios de psicologia, chegou-se ao objetivo desta pesquisa: compreender como foi desenvolvida a sexualidade das mulheres e como a vivenciam, e, ainda, como a psicoterapia na abordagem gestáltica pode contribuir para esse aspecto de suas vidas.

Após essas notas introdutórias acerca do tema desta pesquisa, é importante descrever como a pesquisa é apresentada. Ela se inicia com a definição do método fenomenológico de Giorgi (1985), a descrição dos participantes e do procedimento adotado neste estudo. Em seguida, nos resultados e discussão, são abordados alguns conceitos da abordagem gestáltica que advêm das bases teóricas - teoria organísmica, teoria de campo e psicologia da Gestalt - como o contato, funções de contato, figura e fundo, relação pessoa-ambiente, dentre outros, para uma maior compreensão teórica das categorias apresentadas. Por fim, são feitas algumas considerações, a fim de refletir o estudo realizado. As entrevistas e suas reduções são anexadas na íntegra, para posteriores utilizações.

\section{Método}

\subsection{Pesquisa Fenomenológica}

Neste estudo, utilizou-se a entrevista semidirigida como instrumento para apreender a vivência da sexualidade das participantes. Segundo Gomes (1997), a entrevista semiestruturada serve como veículo de comunicação e forma de fazer conhecida a experiência. Com ela explora-se o mundo vivido do entrevistado e se procura o sentido atribuído pelo sujeito a esse mundo. O roteiro de perguntas foi elaborado tendo como tema a sexualidade, mas deixando espaço para que as entrevistadas tivessem liberdade de expor pontos não questionados, caso os julgassem importantes.

Para análise das entrevistas realizadas, recorreu-se ao método de pesquisa fenomenológica elaborado por Amadeo Giorgi (1985), que parte de transcrições de entrevistas, e apresenta quatro passos. O primeiro consiste na leitura da descrição, a fim de formular uma idéia do que foi abordado e servir de embasamento para o próximo passo. O segundo é a releitura da descrição, com o objetivo de discriminar as unidades significativas, 
identificadas sempre que o pesquisador nota uma mudança de sentido no discurso do sujeito e que responda à pergunta proposta. Este passo é realizado sem a alteração da linguagem usada pelo entrevistado. Após serem delimitadas as unidades de sentido, o pesquisador a elas retorna e as traduz em uma linguagem psicológica, com ênfase ao fenômeno investigado. Essa transformação é necessária, pois a descrição do sujeito expressa realidades múltiplas, e o aspecto que se deseja captar da experiência é o psicológico. Por fim, as unidades de sentido são sintetizadas e transformadas em categorias, que correspondem ao agrupamento de unidades de significado, buscando traduzir, de maneira mais ampla, a essência da fala do entrevistado (Giorgi, 1985; Moreira, 2002; Andrade, 2007; Ferreira, Leão \& Andrade, 2008; Suassuna \& Holanda, 2009).

\subsection{Colaboradoras}

A pesquisa foi realizada com três mulheres que estão em psicoterapia na abordagem gestáltica. Sua identidade está preservada e são utilizados nomes fictícios no decorrer deste trabalho. Elas foram convidadas a participar deste estudo por suas respectivas terapeutas, por meio de um folder-convite.

A primeira entrevistada foi Gabriela, de 32 anos, solteira, sem filhos, com formação superior em pedagogia. Gabriela considera-se disponível para novas experiências sexuais, gosta de sexo e tem grande interesse por ele e aponta a importância de uma boa relação sexual em seus relacionamentos amorosos. Percebe que seu interesse por questões relacionadas ao sexo contribui para a vivência de sua sexualidade.

A segunda foi Renata, de 28 anos, também solteira, sem filhos, e com formação superior em letras. Renata teve sua primeira experiência sexual com 27 anos, apesar de ter percebido sua sexualidade desde os 10 anos. Considera que a dificuldade em lidar com sua obesidade prejudica-a na vivência de sua sexualidade.

A terceira entrevistada foi Débora, de 38 anos, casada há 15 anos, mãe de dois filhos, com formação superior em fisioterapia. Débora alega não sentir falta de sexo no seu cotidiano; a preocupação com a família e o longo casamento têm grande influência sobre a vivência de sua sexualidade.

As entrevistas semiestruturadas foram realizadas individualmente, e tiveram como perguntas norteadoras: como você iniciou sua vida sexual? Como ela se desenvolveu? Como ela está atualmente? Você conversa sobre sua sexualidade na sua terapia? Você percebeu alguma influência da psicoterapia na sua vida sexual? As três primeiras perguntas buscam investigar como a sexualidade foi desenvolvida e como é vivenciada pelas mulheres, e as duas últimas, compreender como a Gestalt-terapia pode influenciar essa vivência.

\section{Resultados e Discussão}

Após a aplicação do método de Giorgi (1985), chegouse a cinco categorias que evidenciam a essência do que fora percebido nesta pesquisa. Essas categorias são: desenvolvimento da sexualidade, vivência da sexualidade, contato, funções de contato e terapia, sexualidade e desenvolvimento pessoal, como se vê a seguir.

\subsection{Desenvolvimento da Sexualidade}

A sexualidade, presente desde o nascimento, tem um tempo e ritmo próprios para ser vivenciada pela pessoa. Uma das colaboradoras do trabalho destaca que a sexualidade é intuitiva, mas que não se aprende em determinado momento, que sempre esteve presente em sua vida:

Uma parte acho que é inconsciente, é mais dedutiva do que consciente, por exemplo, eu me recordo de criança pequena, que eu mexia em mim, me masturbava eu acho... (Débora)

A vivência da sexualidade como tal, ocorre na puberdade, que se inicia nas meninas com o desenvolvimento mamário, aparecimento inicial dos pelos pubianos e da menarca, seguido por um maior desenvolvimento dos seios e pelos pubianos (Duarte, 2010). Nota-se que o desenvolvimento físico e a menarca foram enfatizados como marcos por duas colaboradoras.

Foi cedo. Foi com uns onze ou doze anos. Depois que eu menstruei, acho que é sempre depois que a gente menstrua, né?... (Gabriela)

E eu tive um desenvolvimento físico muito precoce, eu menstruei aos dez anos, então minha experiência com a sexualidade feminina, não com sexo mesmo, foi muito precoce... (Renata)

As rápidas transformações corporais contribuem para o interesse das adolescentes pelo conhecimento de si mesmo, tanto de sua identidade sexual como de seu corpo. Nesse processo, ocorre a manipulação das partes do corpo, a descoberta de sensações eróticas, de zonas erógenas e a experimentação da masturbação (Seixas, 1998). Conforme Ginger (2007), admite-se atualmente que a masturbação é necessária e natural no desenvolvimento sexual, pois prepara a função sexual e beneficia especialmente o orgasmo feminino.

Neste estudo pôde-se notar com clareza as afirmações dos autores nos trechos em que duas colaboradoras descrevem suas descobertas físicas por meio da masturbação, e a percepção de sensações eróticas despertadas em seus corpos: 
Eu acho que aos poucos eu comecei a descobrir comigo mesmo... Comigo, eu me tocando essas coisas (...). Já me tocava, já me sentia (...). Quando eu via coisas eróticas eu sentia... (Gabriela)

A passagem à sexualidade com parceiro é a mudança de maior repercussão na adolescência (Heilborn, 2006a). Após o desenvolvimento sexual inicial, no qual ocorrem as descobertas do próprio corpo e das sensações prazerosas, aproxima-se o momento do ato sexual propriamente dito. Para Altmann (2007), a primeira relação sexual ideal deve acontecer em um relacionamento amoroso, o que pode demonstrar a capacidade do indivíduo em manter uma ligação afetiva. Assim, a experiência sexual é a consequência da concretização do vínculo amoroso.

Percebe-se essa importância com uma colaboradora, que mesmo tendo um desenvolvimento sexual precoce, com um grande conhecimento de seu corpo, e de sua sexualidade, aguardou estar em um relacionamento estável para ter a sua primeira relação sexual:

Mas, segurando, segurando [o desejo sexual] (...). Eu tive o meu primeiro namorado. Aí depois que a gente começou a namorar, foi depois de dois anos, nós dois fomos descobrindo... Aí aconteceu... (Gabriela)

As primeiras relações sexuais não foram consideradas como prazerosas por duas participantes, mas, com a aquisição de maior experiência, o ato para elas tornou-se agradável, possibilitando satisfação:

Não foi às mil maravilhas na primeira vez, foi com o tempo (...). Hoje depois de vários relacionamentos, depois de vários namoros, eu acho que eu posso falar que eu me satisfaço... Eu me satisfazia também... Mas hoje eu me satisfaço mesmo, homem-mulher... (Gabriela)

Heilborn, Cabral e Bozon (2006) mostram dados concordantes com os obtidos nesta pesquisa. Segundo os autores, o maior tempo transcorrido de vida sexual está relacionado a um maior repertório sexual, e essa experiência pode ser tanto com o mesmo parceiro, quanto com vários parceiros.

\subsection{Vivência da Sexualidade}

De acordo com Heilborn (2006b), as distintas formas de interpretar as relações sexuais geram impactos diversos na forma de experienciar a sexualidade, o que é notado na diversidade de vivências sexuais percebidas nesta pesquisa.

Reis (1992) assinala que existe diferenças entre o discurso acerca da sexualidade e como ela é vivida pelos indivíduos. Na fala, trata-se de algo natural, normal, voltado para o prazer, mas ela é vivenciada com preconceitos, que podem provocar insatisfação e sentimentos de culpa. O relato de uma entrevistada confirma a análise do autor:

Em algumas vivências minhas, quando eu perdi a minha virgindade (...). Eu tive algumas dificuldades para lidar... O discurso é liberal, eu acho que é liberal, mas na hora que vai vivenciar a coisa é um pouco diferente... (Renata)

Outros fatores que influenciam a sexualidade e nela interferem são externos, como dupla jornada, preocupação com o trabalho, vida doméstica e maternidade (França \& Baptista, 2007; Seixas, 1998). A sobrecarga que eles geram nas mulheres reflete-se diretamente na sexualidade, podendo deixar de ser relevante, como relata uma colaboradora:

Eu estava sem trabalho, desesperada para pagar as minhas contas, a escola do meu filho atrasada, sem dinheiro para comprar comida, sem gasolina para ir e voltar, eu vou pensar em sexo? Não cabe na minha cabeça... (Débora)

Por estar desempregada, passando por dificuldades financeiras, a colaboradora não conseguia pensar em sexo. Família, trabalho e preocupações do cotidiano ocupam de tal forma sua vida que não há espaço para o sexo nesse momento.

Segundo a psicologia da Gestalt, a pessoa saudável elege uma necessidade, que é denominada figura. Ela é determinada pela tarefa que a natureza do organismo exige naquele momento (Koffka, 1975). Uma colaboradora afirma ter uma escala de valores que define o que se destaca como figura e o que permanece ao fundo em sua vivência. A saúde da família, educação dos filhos e alimentação emergem como a figura, e percebe-se a vivência sexual, por muitas vezes, não sendo figura:

Acho que eu devo ter uma escala de valores, então primeiro precisa estar todo mundo bem, a saúde de todo mundo precisa estar boa, todo mundo precisa estar na escola, com educação, todo mundo precisa ter comido. Tudo isso é mais importante do que o sexo, ou do que essa parte da sexualidade... Se isso tudo estiver bem, aí eu vou pensar numa boa numa relação... (Débora)

A construção da escala de valores da colaboradora é definida por suas necessidades pessoais e sofre também influência social e cultural. Em diversos momentos, o comportamento de Débora é o esperado das mulheres. De acordo com Seixas (1998), a mulher recebe uma educação alienante e é preparada para perceber as necessidades dos outros, deixando a sua própria de lado. 
A variedade de vivências da sexualidade encontradas nesta pesquisa trouxe à tona a abertura em relação ao sexo. Segundo Heilborn (2006b), a revolução sexual que tornou mais liberais códigos de conduta que antes eram limitados, permitiu, sobretudo às mulheres, uma maior liberdade para tratar o tema da sexualidade (Heilborn, 2006b). Alguns trechos de uma entrevista corroboram a análise da autora:

Eu acho que é muito importante também o casal conversar sobre suas vontades, seus desejos. Eu converso sobre fantasias. (...). Falamos e fazemos as nossas vontades, a gente se entrega mesmo. Ele também. Acho que é muito bom esse negócio da entrega. (...). Percebe a forma clara que eu tenho... Que eu não ponho dificuldade no sexo... (Gabriela)

A colaboradora demonstra facilidade em tratar com seu parceiro de aspectos relacionados à sexualidade e percebe que a liberdade e a comunicação clara contribuem para a entrega de ambos. A abertura do casal proporciona também uma sintonia dos dois, demonstrada pela preocupação recíproca e pela cumplicidade, como relata a entrevistada:

Tanto eu preocupar com ele, como ele preocupar comigo. Tem que ter cumplicidade e ser recíproco. Os dois exporem a vontade, e não esconder, eu deixo isso claro... (Gabriela)

Outra vivência da sexualidade encontrada foi a experiência negativa na primeira relação sexual. Para Altmann (2007), o ideal da primeira relação é muito forte, e não se trata de valorizar a virgindade por ela mesma, mas de dar especial atenção essa experiência. Assim, ao perceber que ela não foi como esperava, a colaboradora diz que sentiu-se mal e se responsabiliza por ter estragado esse momento de sua vida:

Sempre quando eu penso em sexo, quando eu penso na minha primeira vez... Eu penso: "Nossa! Como eu consegui?... Como eu consegui destruir um momento tão especial da minha vida”... Eu destruí, eu estraguei esse momento tão especial da minha vida, e tudo o mais... (Renata)

Ribeiro (2006) pondera que nenhum ser se autoregula sozinho ou com base nele mesmo, pois todos os seres se auto-regulam no mundo e com base nele. Assim, um dos fatores que contribuiu para a primeira relação sexual não ser como a colaboradora esperava foi não ter um relacionamento longo com o parceiro. Atualmente, ela continua sem um relacionamento, sem ter resolvido essa questão, e afirma estar se tornando um ser assexuado:
Não namorava, não tinha um relacionamento longo, e... Como isso tem se perpetuado (...), a tendência agora é eu me "assexuar". [Risos] No momento eu acho que estou me tornando um ser "assexuado". (...). Eu continuo "assexuada". Eu ainda não resolvi isso... (Renata)

Culturalmente, a sexualidade feminina vincula amor ao sexo, ao passo que da masculina, se espera uma vida sexual ativa, mesmo sem a presença do afeto (Dall'Agnol, 2003). Esses padrões de comportamento diferenciados são mantidos e cada um dos gêneros deve saber o que fazer em relação ao outro (Santos \& Silva, 2008). A colaboradora demonstra em seu relato que essa concepção cultural é presente em sua vivência. Para ela, a mulher fica disposta a ter relações sexuais se estiver bem, e para o homem, a relação sexual é um meio, um instrumento para sentir-se bem. Ela alega não conseguir relaxar para ter uma relação sexual e entende que o comportamento do homem seja o oposto:

A diferença entre homem e mulher é: a mulher se não estiver relaxada, ela não consegue ter uma boa relação sexual. E o homem se não tiver uma relação sexual não consegue ficar relaxado. (...). Eu não consigo também me desligar para pensar: "Hoje eu preciso ter uma relação sexual"... E o homem é assim, na minha opinião... (Débora)

Envolvendo homens e mulheres, o comportamento sexual não é algo que diga respeito ao plano individual, mas ao interpessoal (Taquette \& Vilhena, 2008). Em um relacionamento amoroso, o exercício da sexualidade supõe o contato com o outro, não é possível manter o outro distante. Para duas entrevistadas a sexualidade desempenha papel importante nessas relações:

Eu acho que em um relacionamento, tem que ser tudo. E em relação ao sexo também tem que ser assim... Eu não ponho primeiramente o sexo, lógico. Como eu falei, é fundamental, mas não 100\%. Mas é muito importante... (Gabriela)

Mesmo sendo percebida como crucial para o relacionamento, a sexualidade é alvo de dificuldades que acompanham a vida amorosa de casais. Dentre elas, para Ginger e Ginger (1995), uma das mais comuns e talvez mais negadas, seja a rotina. Ela se instala sem que o casal a perceba, e dia após dia impede a criatividade e interrompe os canais de comunicação.

Uma colaboradora relata:

É interessante como hoje, eu tenho quinze anos de casada já, eu não sinto falta de um relacionamento, é interessante... (Débora) 
Ela se admira ao notar que após quinze anos de casada, não mais sente falta de sexo, deixando entrever que talvez tenha sido diferente no início do relacionamento. A mudança em relação ao sexo reflete-se na vivência dessa colaboradora quando ele passa a ser percebido como algo necessário à manutenção do casamento, e não como algo desejado. Para ela há mudança de figura no decorrer dos anos de casamento: no início, era a sexualidade, atualmente é a manutenção do seu casamento:

Acho que é mais necessária para a manutenção de um casamento, de um relacionamento de casal... (Débora)

\subsection{Contato}

O contato é destacado por Ribeiro (2006) como conceito essencial da Gestalt-terapia. Para o autor, contato é a emoção experienciada, a energia que impulsiona a mudança e que dá sentido à realidade (Ribeiro, 2007). É fundamental para o crescimento, e, por meio dele, é possível mudar a si próprio e a percepção do mundo (Polster \& Polster, 2001; Perls, Hefferline \& Goodman, 1997). Perceber-se é, então, entrar em contato consigo mesmo, com emoções e conceitos pessoais, o que pode acontecer em virtude de experiências vividas, como relatado por uma das participantes da pesquisa:

O conceito que eu descobri que eu tinha. Não sei se eu descobri, eu percebi. Na verdade eles estavam ali, e em algum momento a experiência só fez aflorar algumas dificuldades que estavam ali embolando dentro de mim. (...). Aí tem um fator inerente, à minha formação, à minha dificuldade em lidar com a minha obesidade, o pré-conceito que eu tenho e que acaba influenciando. E eu vi que influenciaram também nessa decisão de fazer, de transar, de fazer sexo... (Renata)

A experiência sexual da colaboradora permitiu que ela entrasse em contato com seu preconceito, sua dificuldade em lidar com a obesidade, dos quais não estava consciente até então, mas que permeiam sua vida. $\mathrm{O}$ aspecto especial do contato, de acordo com Polster e Polster (2001), é a possibilidade de estar em contato consigo mesmo e ocorre graças à capacidade de o indivíduo dividir-se em observador e observado. A participante, ao observar-se, pôde perceber aspectos de si mesma que não estavam claros até esse momento e descobrir o que motivou sua atitude, ela declara:

Eu não me acho... Isso é o que me pesa mais... Eu não me acho capaz. É o ponto chave com a minha sexualidade. Eu descobri que foi isso que me fez precipitar (...). É a falta de ainda não conseguir me enxergar como eu realmente sou. Eu tenho uma dificuldade enorme de lidar com a minha obesidade, com meu corpo... (Renata)

Esta experiência permitiu que ela compreendesse sua real dificuldade, e se encontrasse. Estar presente em si mesmo, olhar para si próprio e se reconhecer é estabelecer contato (Ribeiro, 2006). A colaboradora demonstra grande dificuldade em manter esse contato. Tem conhecimento de sua obesidade, porém não consegue lidar com ela de forma a sentir-se bem. Nota-se que o seu sentimento de incapacidade em relação à sexualidade é influenciado pela obesidade, o que vai ao encontro do que afirma Heilborn (2006b): a obtenção de parceiros sofre intervenção direta da atração que o corpo pode exercer sobre outras pessoas.

\subsection{Funções de Contato}

As formas de entrar em contato com o outro, com o mundo e consigo mesmo são a visão, a audição, o olfato, o paladar e o toque. Além desses cinco modos existe também o falar e o movimentar-se (Polster \& Polster, 2001). Nas entrevistas realizadas com as participantes, fica evidente a presença e a importância de algumas das funções de contato na descoberta e na vivência de sua sexualidade. A seguir observam-se como as funções mencionadas pelas entrevistadas contribuem para a sua sexualidade.

Todas as participantes deste estudo fizeram referência ao toque, que Polster e Polster (2001) consideram a forma mais óbvia de e contato. $\mathrm{O}$ toque foi relevante para suas descobertas sexuais, tanto por meio da masturbação, como do toque mútuo, com o parceiro. Tocar-se no início do desenvolvimento da sexualidade possibilitou fazer contato com o próprio corpo, conhecê-lo e descobrir formas de prazer que enriqueceram suas experiências sexuais.

As colaboradoras relatam suas experiências com o toque:

E eu acho que aos poucos eu comecei a descobrir comigo mesmo... Comigo, eu me tocando essas coisas (...). Eu sabia onde ele podia me tocar que eu sentia tal prazer, entendeu? Eu já conhecia foi fácil... (Gabriela)

Acho que eu tinha uns quinze anos, foi a descoberta de o outro mexer em você, do outro te tocar... (Débora)

Eu comecei a me masturbar muito cedo, eu sabia o que era masturbação e me masturbava muito cedo... (Renata)

A fala como função de contato pode ser usada com diferentes entonações, e assim assumir diversos signifi- 
cados, revelando interesse verdadeiro ou apenas o cumprimento de uma norma social (Polster \& Polster, 2001). Essa função fica evidente nos trechos em que duas participantes mencionam a importância da fala no decorrer da experiência sexual:

Eu percebo porque, tanto ele quanto eu, falamos e fazemos as nossas vontades, a gente se entrega mesmo... (Gabriela)

A gente fala sobre isso, eu falo: "Gosto assim, não gosto assim. Faz assim, vira aqui”. Eu consigo falar das coisas que me dão mais prazer, super numa boa... (Débora)

Falar com o parceiro sobre sexo, do que gosta, de suas vontades, no momento do ato sexual, é importante para as colaboradoras. Por meio da fala, o casal entra em contato com as preferências um do outro, e, assim, o sexo fica melhor e a entrega é intensa.

Percebe-se que, por mais que seja doloroso falar de sua experiência sexual, entrar em contato com sua ferida por meio da fala, possibilita à colaboradora a contínua construção de sua sexualidade. Ela pode ressignificar sua experiência pela renovação que figura e fundo promovem formando e destruindo gestalten (Ribeiro, 2007; Yontef, 1998). O contato, como enfatiza Polster e Polster (2001), nem sempre leva à felicidade, mas, como percebeu a colaboradora, ainda assim é fundamental para a formação de uma pessoa:

Falar é reabrir, sempre. Reviver, retomar, e ainda não é fácil falar. Mas é sempre bom, por mais que doa... Para mim, é engraçado, é bom mexer na ferida, por mais dolorosa que ela seja. Eu tenho a impressão que ou ela vai cicatrizando aos poucos, ela vai virando outra pele para sofrer outras alterações... (Renata)

O cheiro, apesar de muito primitivo, é uma das funções mais desprezadas, de acordo com Polster e Polster (2001). Neste estudo, essa função de contato foi mencionada por apenas uma das colaboradoras o que corrobora a afirmação do autor. Ficou evidente, pela entonação de sua voz que considera o cheiro um importante canal de contato com seu parceiro, pois sente-se estimulada sexualmente pelo cheiro de homem:

Gostar de estar fazendo, de gostar de estar com o homem, de sentir a pegada, o cheiro, essa coisa masculina mesmo, que dá... (Gabriela)

Uma das formas mais interessantes de contato e interação dá-se pelo olho, que tanto capta quanto transmite sensações, segundo Lilienthal (2005). Muitas vezes, essa captação tem função intermediária, usada para dar acesso a outras informações que se deseja alcançar
(Polster \& Polster, 2001). Assim o fez uma colaboradora, que, por meio da visão, teve acesso a cenas de sexo em filmes e pôde ir tomando conhecimento de sua própria sexualidade:

Eu gostava mesmo de ver filmes pornôs, eu via. (...). A forma como a mulher agia, como o homem penetrava, tudo... (Gabriela)

Outra função de contato presente nos relatos das entrevistadas é o ouvir. Polster e Polster (2001) afirmam que, de forma plena, o ouvinte se integra ao que está escutando e não apenas registra as palavras que chegam ao seu ouvido. Ele ouve também o significado que aquelas palavras têm para ele, e como elas o tocam. A colaboradora envolvia-se de tal forma com os sons emitidos nos filmes pornôs que se sentia excitada sexualmente, como relata:

Eu tinha assim, um interesse. Acho que é porque eu ouvia, eu via. De vez em quando, quando aparecia, eu sentia... (Gabriela)

\subsection{Terapia, Sexualidade e Desenvolvimento Pessoal}

As participantes não mencionaram a presença do tema sexualidade em suas terapias, nem a sua contribuição direta nessa área de suas vidas, porém deram importância considerável ao autoconhecimento alcançado com a psicoterapia gestáltica.

Com base na teoria de campo de Lewin (1973), segundo a qual uma mudança ocorrida em uma região afeta todas as outras, em graus variados (Lewin, 1975; Ribeiro, 1985; 2007), pode-se inferir e compreender que a terapia teve influência na vivência da sexualidade das colaboradoras. As participantes, ao conhecerem-se melhor como mulher, conseguiram abrir-se para o mundo e para as relações sociais. Vivendo de forma mais plena, conhecendo-se e estabelecendo melhores relações, a sua sexualidade também foi afetada.

A teoria organísmica faz afirmação semelhante ao enunciar que um acontecimento em uma parte do organismo afeta o todo, pois o organismo comporta-se como um todo integrado, e não como várias partes diferentes (Hall, Lindzey \& Campbell, 2000).

Os depoimentos que se seguem revelam a importância da terapia em suas vidas:

Foi muito bom, porque eu sempre fui muito fechada, muito calada... E a terapia me fez poder me abrir, poder falar. Porque pra mim... O falar por si só já foi um processo de autoconhecimento. Então a terapia me ajudou em todos os sentidos, de me descobrir, saber me articular, saber falar de mim... (Renata) 
Ajuda bastante também [a terapia]... Eu estou me conhecendo ainda melhor. Na parte da sexualidade eu já me conhecia... Eu me conheço melhor e está me ajudando na forma de eu agir... (Gabriela)

\section{Considerações Finais}

Durante o processo que envolveu a execução desta pesquisa pôde-se perceber quão delicado é tratar da sexualidade feminina. Os desafios iniciaram-se com a escolha da melhor forma de reunir mulheres dispostas a participarem de uma pesquisa com esse tema. Apesar dessa dificuldade, foi interessante observar que as mulheres que se dispuseram a colaborar tiveram facilidade para abordar o assunto.

Outro obstáculo foi encontrar referências sobre o tema na abordagem gestáltica, embora haja estudos sobre sexualidade feminina dos prismas biológico, social, de psicopatologia e de saúde pública, visto que fatores históricos, sociais e culturais exercem grande influência na construção da sexualidade feminina. Assim, para compreender como a mulher vivencia sua sexualidade no dia a dia, buscou-se relacionar o que foi encontrado na pesquisa, o que estudiosos do tema de diversos enfoques teóricos afirmam e alguns princípios teóricos da Gestalt-terapia. Os resultados encontrados permitem destacar alguns pontos que ajudam a esboçar os contornos da sexualidade feminina.

Conforme as entrevistadas, o desenvolvimento sexual inicia-se com o toque do próprio corpo e a masturbação, que são importantes para o autoconhecimento físico e sexual das mulheres. Posteriormente, elas se abrem ao contato com um parceiro, e o autoconhecimento que adquiriram anteriormente é fundamental para uma experiência prazerosa com o parceiro escolhido.

Percebeu-se que são amplas e variadas as vivências da sexualidade, e que as etapas da vida em que se encontram as mulheres entrevistadas influenciam a sexualidade. Elas, quando solteiras, buscam na sexualidade a satisfação, uma forma de sentir prazer, e se aproximar do outro. Após o casamento, delegam ao sexo o papel de mais um dos componentes da união, e ele se dá mais em razão do casamento que do desejo. A forma como as experiências sexuais são percebidas pelas mulheres também interfere na direção que estabelecem para a sua sexualidade. Experiências ruins podem provocar uma reflexão relativa ao modo de relacionar-se e aquilo que buscam com o sexo, entrevendo até a possibilidade até de assexualizar-se, como declarou uma colaboradora, enquanto essas questões não se resolverem.

Na pesquisa, fica evidente que quanto mais fazem uso das funções de contato e atribuem a elas valor, explorando toque, olhar, fala, cheiros, e tudo quanto for possível, mais as experiências sexuais são ricas. Por terem exercitado as funções de contato as mulheres sentem-se mais estimuladas, conseguem entregar-se mais ao momento e ao parceiro e pelos relatos, apresentam maior desenvoltura sexual. Assim, estarem atentas a si mesmas, e permitirem-se expor e explorar suas vontades possibilitou-lhes uma vivência mais plena da sexualidade feminina.

Para as entrevistadas a psicoterapia não apareceu como espaço em que emergissem temas relacionados à sexualidade. As mulheres, que não procuram a psicoterapia por dificuldades sexuais específicas, dela se utilizam para resolução de conflitos pessoais de outras naturezas. Dificuldades familiares, profissionais de relacionamento, de busca de autoconhecimento ocupam o espaço de suas sessões de psicoterapia, de forma que a sexualidade e temas próximos ainda não foram explorados. Uma possível falha desta pesquisa foi não ter deixado explícito no folder-convite que as Gestalt-terapeutas deveriam convidar pacientes que, em seus processos psicoterapêuticos, abordassem o tema da sexualidade. Talvez fosse interessante retomar o tema desta pesquisa em outro momento, pois a sexualidade, de alguma forma, tornou-se figura após as entrevistas.

Assim, embora muito se fale que os valores culturais estão mudando, o que promoveria mais liberdade para as mulheres tratarem o tema, o que pode se perceber é que ainda há muito caminho pela frente. Esta pesquisa foi um dos passos para a compreensão da vivência sexual feminina, porém fica claro que o tema não se esgota pela diversidade de vivências encontradas. Trata-se, portanto, de vasto campo de pesquisa, até mesmo para Gestalt-terapeutas.

Ao final deste trabalho, notou-se que algumas questões a respeito da sexualidade feminina ainda podem ser mais exploradas, a fim de ajudar a compreender esse aspecto tão importante e tantas vezes negligenciado de suas vidas. O embasamento teórico da Gestalt-terapia oferece subsídios para a compreensão da melhora da sexualidade e mesmo que essa não seja abordada diretamente na psicoterapia, seria enriquecedor aprofundar a compreensão do como as mulheres percebem essa ajuda. Compreender como a relação com o próprio corpo influencia a sexualidade feminina, também seria extremamente interessante em virtude do que se pôde perceber nos relatos, e, ainda, tendo em vista o muitas vezes inalcançável padrão de beleza ao qual as mulheres socialmente se submetem.

\section{Referências}

Abbagnano, N. (1999). Dicionário de filosofia. São Paulo: Martins Fontes.

Altmann, H. (2007). Educação sexual e primeira relação sexual: entre expectativas e prescrições. Revista Estudos Feministas, [on-line], 15(2), 333-356. Disponível em: < http:// www.scielo.br/scielo.php?script=sci_arttext\&pid=S0104026X2007000200004\&lng=en\&nrm=iso>. Acesso em 30 mar. 2010. 
Andrade, C. C. (2007) A vivência do cliente no processo psicoterapêutico: um estudo fenomenológico na Gestalt-terapia. Dissertação de Mestrado não publicada, Universidade Católica de Goiás, Goiânia.

Chaer, L. (2006) Uma pesquisa sobre holismo e educação holística. Fragmentos de Cultura, [on-line], 16(4), 555-566. Disponível em: http://seer.ucg.br/index.php/fragmentos/article/viewPDFInterstitial/44/42. Acesso em 30 mar. 2010.

Dall'Agnol, R. S. (2003). A sexualidade no contexto contemporâneo: permitida ou reprimida? Psic - Revista de Psicologia da Vetor Editora, [on-line], 4(2), 26-31. Disponível em: http:/ pepsic.bvs-psi.org.br/pdf/psic/v4n2/v4n2a04.pdf. Acesso em 30 mar. 2010.

Duarte, M. deF. da S. (2010). Maturação física: uma revisão da literatura, com especial atenção à criança brasileira. Cadernos de Saúde Pública, [on-line], 9(1), 71-84. Disponível em: <http:// www.scielo.br/scielo.php?script=sci_arttext\&pid=S0102$311 X 1993000500008 \& \operatorname{lng}=$ pt\&nrm $=\bar{i}$ so $>$. Acesso em 16 jun. 2010.

França, I. S. X. de, \& Batista, R. S.(2007). A construção cultural da sexualidade brasileira: implicações para a enfermagem. Revista Brasileira de Enfermagem, [on-line], 60(2), 202-206. Disponível em: <http://www.scielo.br/scielo.php? script $=$ sci_arttext\&pid=S0034-71672007000200014\&lng $=$ en\&nrm=iso $>$. Acesso em 12 jun. 2010.

Ferreira, L. C., Leão, N. C., \& Andrade, C. C. (2008). Viuvez e luto sob a luz da Gestalt-terapia: experiências de perdas e ganhos. Revista da Abordagem Gestáltica, [on-line], 14(2), 153-160. Disponível em: http://pepsic.bvsalud.org/scielo. php?script=sci_arttext\&pid $=$ S1809-68672008000200002\&lng=es\&nrm=iso. Acesso em 30 mar. 2010.

Giorgi, A. (1985). Sketch of a psychological phenomenological method. Em A. Giorgi (Org.), Phenomenology and psychological research (pp. 8-22). Pittsburg: Duquesne University Press.

Ginger, S. \& Ginger, A. (1995). Gestalt: uma terapia do contato. São Paulo: Summus.

Ginger, S. (2007). Gestalt: a arte do contato: nova abordagem otimista das relações humanas. Petrópolis: Vozes. São Paulo: Summus.

Gomes, W. B. (1997). A entrevista fenomenológica e o estudo da experiência consciente. Psicologia USP, [on-line], 8(2), 305-336. Disponível em: <http://www.scielo.br/scielo.php? script=sci_arttext\&pid=S0103-65641997000200015\&lng $=$ en\&nrm=iso $>$. Acesso em 30 mar. 2010.

Hall, C. S., Lindzey, G., \& Campbell, J. B. (2000). Teorias da personalidade. Porto Alegre: Artes Médicas.

Heilborn, M. L., Cabral, C. S. \& Bozon, M. (2006). Valores sobre sexualidade e elenco de práticas: Tensões entre modernização diferencial e lógicas tradicionais Em M. L. Heilborn, E. M. L. Aquino, M. Bozon \& D. R. Knauth (Orgs.), O aprendizado da sexualidade: reprodução e trajetórias sociais de jovens brasileiros (pp. 207-266). Rio de Janeiro: Garamond/Fiocruz.

Heilborn, M. L. (2006a). Experiência da sexualidade, reprodução e trajetórias biográficas juvenis. Em M. L. Heilborn, E. M. L. Aquino, M. Bozon \& D. R. Knauth (Orgs.), O apren- dizado da sexualidade: reprodução e trajetórias sociais de jovens brasileiros (pp. 29-59). Rio de Janeiro: Garamond/ Fiocruz.

Heilborn, M. L.(2006b). Entre as tramas da sexualidade brasileira. Revista Estudos Feministas, [on-line], 14(1), 43-59. Disponível em: <http://www.scielo.br/scielo.php?script= sci_arttext\&pid=S0104-026X2006000100004\&lng=pt\&nrm =iso $>$. Acesso em 30 mar. 2010.

Koffka, K. (1975). O campo ambiental: figura e fundo. Em K. Koffka, Princípios da psicologia da gestalt. São Paulo: Cultrix.

Lewin, K. (1973). Princípios de psicologia topológica. São Paulo: Cultrix.

Lewin, K. (1975). Teoria dinâmica da personalidade. São Paulo: Cultrix.

Lilienthal, L. (2005). De olho no contato. Revista de Psicologia do Instituto Gestalt de São Paulo, 2(2), 43-45.

Lima, P. V. A. (2008). O holismo em Jan Smuts e a Gestalt-terapia. Revista da Abordagem Gestáltica, 14(1), 3-8. Disponível em: < pepsic.bvs-psi.org.br/pdf/rag/v14n1/v14n1a02.pdf>. Acesso em 30 mar. 2010.

Ministério da Saúde. (2006). Direitos sexuais, direitos reprodutivos e métodos anticoncepcionais. Secretaria de Atenção à Saúde, Departamento de Ações Programáticas Estratégicas. Brasília - DF. Disponível em: <http://docs.google.com/vie wer?a $=\mathrm{v} \& \mathrm{q}=$ cache:pmEmCS7X8b4J:portal.saude.gov.br/ portal/arquivos/pdf/cartilha_direitos_sexuais_2006.pdf $>$. Acesso em 30 mar. 2010.

Moreira, D. A. (2002). O método fenomenológico na pesquisa. São Paulo: Pioneira Thomson.

Perls, F., Hefferline, R., \& Goodman, P. (1997). Gestalt-terapia. São Paulo: Summus.

Pinto, E. B. (2002). Sexualidade: um bate-papo com o psicólogo. São Paulo: Paulinas.

Polster, E., \& Polster, R. (2001). Gestalt-terapia integrada. São Paulo: Summus.

Reis, J. R. T. (1992). Cenas familiares, psicodrama e ideologia. São Paulo: Àgora.

Ribeiro, J. P. (1985). Gestalt-terapia: refazendo um caminho. São Paulo Summus.

Ribeiro, J. P. (1997). O ciclo do contato: temas básicos na abordagem gestáltica. São Paulo: Summus

Ribeiro, J. P. (2006). Váde-mecum de gestalt-terapia: conceitos básicos. São Paulo: Summus.

Ribeiro, J. P. (2007). O ciclo do contato: temas básicos da abordagem gestáltica. São Paulo: Summus.

Santos, D. B., \& Silva, R. C. da. (2008). Sexualidade e normas de gênero em revistas para adolescentes brasileiros. Saúde e Sociedade, [on-line], 17(2), 22-34. Disponível em: <http:// www.scielo.br/scielo.php?script=sci_arttext\&pid=S0104$12902008000200004 \& \operatorname{lng}=\mathrm{en} \& \mathrm{nrm}=\mathrm{iso}>$. Acesso em 03 abr. 2010. 
Seixas, A. M. R. (1998). Sexualidade feminina. História cultura, família - personalidade e psicodrama. São Paulo: Editora Senac.

Suassuna, D. \& Holanda, A. (2009). "Histórias" da gestalt-terapia no Brasil: um estudo historiográfico. Curitiba: Juruá.

Taquette, S. R., \& Vilhena, M. M. de. (2008). Uma contribuição ao entendimento da iniciação sexual feminina na adolescência. Psicologia em estudo, [on-line], 13(1), 105-114. <http:/ www.scielo.br/scielo.php?script=sci_arttext\&pid=S1413$73722008000100013 \& \operatorname{lng}=\mathrm{en} \& \mathrm{nrm}=\overline{\mathrm{i}} \mathrm{so}>$. Acesso em: 30 mar. 2010.

Yontef, G. M. (1998). Processo, diálogo e awareness: ensaios em Gestalt-terapia. São Paulo: Summus.
Cínthia Vieira Möller - Psicóloga, especialista em Gestalt-terapia pelo Instituto de Treinamento e Pesquisa em Gestalt-terapia de Goiânia, ITGT. E-mail: cinthiamoller@hotmail.com

Celana Cardoso Andrade - Psicóloga clínica, especialista em Gestaltterapia pelo ITGT, Mestre em Psicologia Clínica pela Pontifícia Universidade Católica de Goiás (PUC-Goiás), Doutoranda pela Universidade de Brasília, UnB, Professora-Supervisora do ITGT, Professora assistente da Universidade Federal de Goiás (UFG). Endereço institucional: Rua 235, s/n - Setor Universitário - CEP: 74.605-050 - Goiânia-GO. E-mail: celana@fe.ufg.br; celana@terra.com.br

Recebido em 30.08.10

Primeira Decisão Editorial em 16.06.11

Aceito em 24.07.11 